\title{
Commercialization of Chinese Youth Network Subculture and Its Social Effects
}

\author{
Ruihui $\operatorname{Han}^{1}$ \\ ${ }^{1}$ Humanities School, Jinan University, Zhuhai, China \\ Correspondence: Ruihui Han, Humanities School, Jinan University, Zhuhai, China. E-mail: \\ hanruihuihh@hotmail.com
}

Received: January 30, 2014

Accepted: March 25, 2014 Online Published: April 29, 2014

doi:10.5539/ass.v10n9p234

URL: http://dx.doi.org/10.5539/ass.v10n9p234

\begin{abstract}
The number of people surfing the internet in China has ranked the top in the world. Among then, the number of the youths occupies the main part. Social sub-cultural phenomenon is formed in the youth stage. The School of Birmingham considered such cultural phenomenon as the mainstream cultural way for youths to oppose the middle class in England in 1950s-1960s. Currently, under the function of commercialization, some features of youth network subculture have some negative social effects.
\end{abstract}

Keywords: youth, subculture, network, culture industry, commercialization

\section{Introduction}

As of the end of June 2013, the scale of Chinese netizens had reached 591 million, ranking the top in the world, (CNNIC, 2013) where youth netizens formed the main part of Chinese netizens.

Youths form a unique cultural phenomenon which cultural constitutes youth network subculture in combination of network new media. China has strived to develop culture industry in recent years, while network culture industry is a major part of Chinese network culture industry. Youth network subculture and commercialization combine together and interact, which has important social influence. Except the economic effect, what are the social effects? Its social effects become the research emphasis of this paper.

\section{Review of the Previous Scholarship}

According to the papers on network culture industry gained from CNKI.net, related researches concentrate on the relationship between China's network culture industry and China's economic development, relevant law and policy researches on development of network culture industry as well as case researches of development of network culture industry in individual provinces in China. The papers on youth subculture gained from CNKI.net are relatively few. There are only 183 papers. The researches on youth subculture focus on performance characteristics of youth subculture and the relations among youth subculture, youth growth and youth education in recent years.

However, the papers on commercialization of youth network subculture and its social effects are very few. The papers related to this paper include: Qiao Lihua's On Juvenile-subculture and Its Value Significance under the Environment of New Media which mainly discusses the influences of new media on youth sub-cultural phenomenon; (Qiao, 2010)Analysis of Network Culture Consumption Based on Lohas idea written by LI Wenming and Lv Fuyu, which mainly discusses network cultural development and consumption trend from the perspective of spiritual consumption. (Li \& Lv, 2013)

\section{The Popular Understanding of the Youth Subculture}

The researches on youth subculture can be dated from 1960s-1970s. The scholars in University of Birmingham collectively wrote Ceremony Resistance to pay wide attention to youth subculture in the working class in British. The researchers considered the popular subculture among the youths formed resistance of mainstream culture of the middle class in British. Since the youths in the grassroots could not enter the mainstream society, they created fashion culture and had the symbolic meaning of resistance.

The earlier youth subculture researcher Cohen claimed that the youth subculture was contemporary and had no future, and it could not solve the practical problems. In China, youth sub-cultural phenomenon has been a 
phenomenon disparaged by others and is regarded as having short life and weak influence. It is even deemed as the manifestation of ignorance. The culture formed by the group of people who were born in 1990s is called "non-mainstream" culture. It is believed that the age of youth is very short, so the subject would identify with the mainstream value as the time of youth passes. Besides, the youth subculture is only a superficial phenomenon. The youth would identify with the mainstream culture strongly when they are confronted with the important decision.

\section{The Formation of the Main Part of the Netizens in China}

It can be found from the findings of China Internet Network Information Center in June 2013 that the number of residents surfing the internet at the age of 20-39 in China occupied the main part, where the proportion of Chinese netizens between 20 and 29 years old is the largest, followed by the netizens between 30 and 39 years old and between 10 and 19 years old.

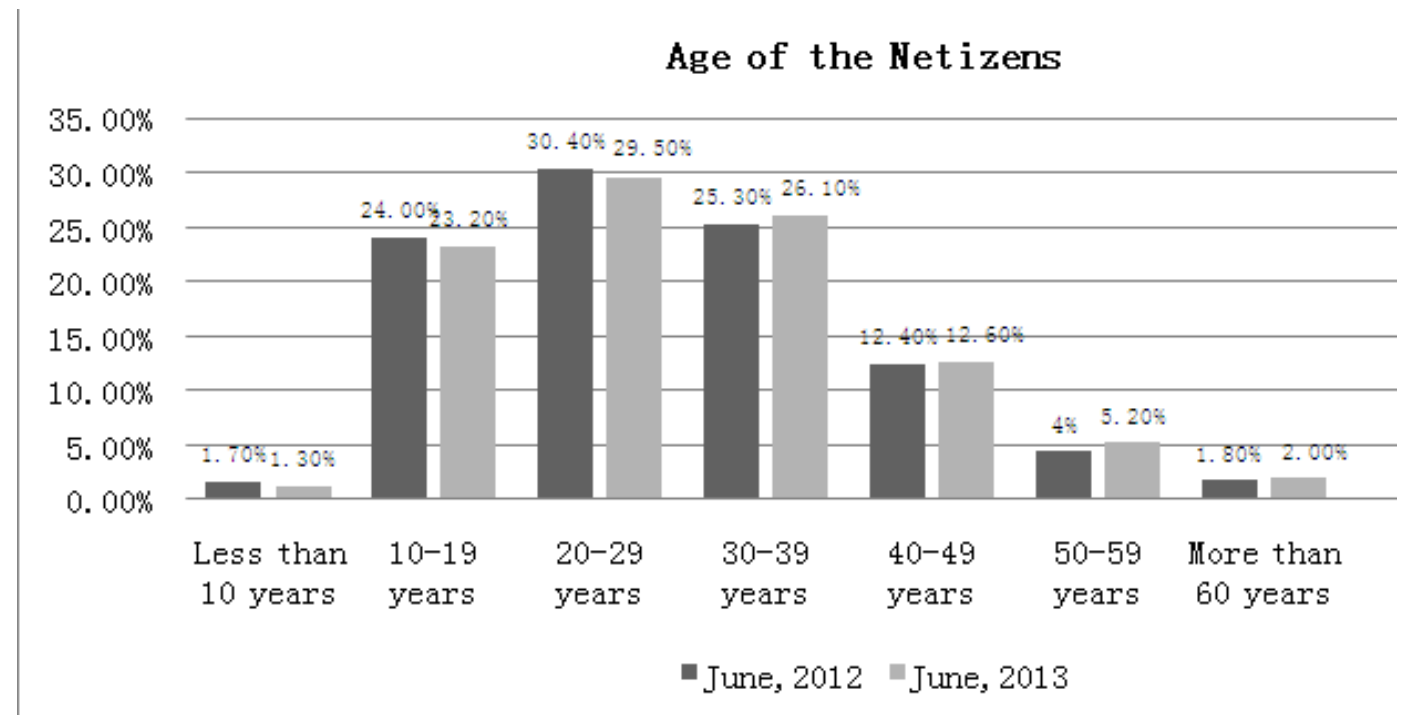

Figure 1. Age of the netizens

It can be found from survey of education background of netizens that the netizens with senior high school, technical secondary school and technical school form the main part of netizens. From the perspective of occupational composition, it can be found that students are in the majority, where student netizens occupied $25.1 \%$ and $26.6 \%$ in December 2012 and June 2013 respectively.

From the income division, it can be found the netizens in middle and low income occupy the main part.

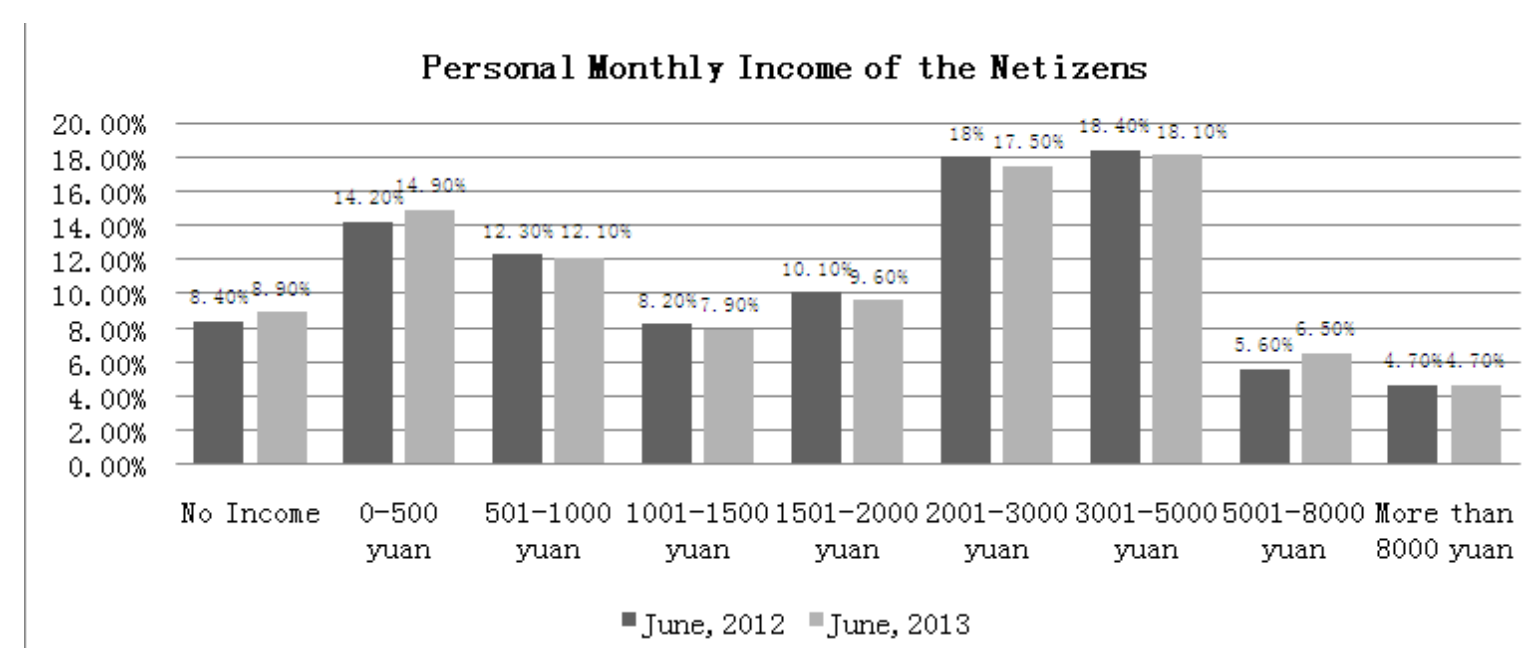

Figure 2. Personal monthly income of the netizens 
The following conclusions can be drawn from the above survey reports:

1) The youths have formed the main part of Chinese netizens.

2) Low-income people and those with low educational background are the main part of Chinese netizens.

\section{The Phenomenon and Characteristics of the Youth Network Subculture in China}

The age level of main Chinese netizens is generally low. Besides, low educational background and low income are the features of Chinese netizen subjects. These lead to unique performance of Chinese netizens in network: high bandwagon effect, releasing oneself in network and weak independent judgment etc. All these form the features of Chinese youth network subculture.

Youth network sub-cultural phenomena emerging in recent years in China include: Kuso culture, non-mainstream culture, autodyne culture and network art etc.

Kuso means to reach the purpose of overturn, deconstruction and fun through imitating classical and traditional banter. In recent years, the earliest kuso widely spread is A Murder Case Caused by A Steamed Bun made by Hu $\mathrm{Ge}-\mathrm{a}$ freelance. This video imitates The Promise directed by a famous director Chen Kaige. The video became very popular soon on internet. "Such ridiculous and cynic video implies the strong realistic criticism. In this sense, A Steamed Bun not only aims at The Promise, but also implies some social conflicts that have not been solved .So the video is very praised by all sectors of society." (Hu, 2008) The 20-min video widely spread. In Chine, people know the existence of this file due to the kuso short-film. Since then, kuso culture has been widely prevalent in Chinese network. Kuso on internet is a cultural phenomenon characterized by the public participation. "Kuso on internet is the manifestation of postmodernism culture. It is opposite to the value that treasured by the mainstream culture circle, highlighting the participation strength of the public in cultural sphere."(Cai \& Liu, 2008)The kuso is very popular on internet just because of its feature of public participation.

The subjects of non-mainstream culture are youths born in 1980s-1990s. In network, many netizens at this age grade have traitorous thoughts, self-assertion and creativity. They often send some weird pictures on network. Beside, they like to pretend decadence and stupid and show the state of "half-youth and half-decadence" with exaggerated techniques. These non-mainstream cultures are often shown in the form of non-mainstream pictures, non-mainstream space and non-mainstream music. Non-mainstream culture is the product of modern society, and it is also the outcome of the industrialization, marketization, democratization and urbanization. (Li, 2008) Non-mainstream culture is a beneficial supplement of the mainstream culture. "Just because of the colorful non-mainstream culture, the mainstream culture becomes more concrete and has stronger and more general effectiveness. The diversified cultural atmosphere makes different cultures conflict and exchange with each other, and it impact on the mainstream culture especially with the result of new idea and culture. On the point of view, the impact and pressure are also the power of motivation, and it makes the mainstream culture avoid the egotistical arrogance.” (Chen \& Zhang, 2013)

In addition, youth autodyne cultural phenomenon frequently appears in the network. Many youths shoot themselves or their articles and download them via network. This shows youths approve and display self-identity and also shows their self-assertion. "Half of the undergraduate or so have the experience of putting their own photos and videos on internet. $2.27 \%$ of them have the experience of putting their private body photos on internet. $11.30 \%$ of them upload their pictures of their own goods and accommodation. $11.5 \%$ of them upload their featured photos. And 5.58\% of them are about the violence, bloodiness, smear and kuso." (Zheng, Pu \& Sun, 2013) These identity construction modes show rebelliousness form of the middle-aged and adult identity construction and show a new cultural phenomenon different from the adult world. Many websites and forums in China especially set autodyne forums which own striking click rate. On the view point of psychology, the self-timer provides the subject with opportunity of self-appreciation, and it makes the subject release the mental pressure and have more virtual sense of achievement. (Wang, 2013)

Network art is also an important youth network sub-cultural phenomenon. It generally refers to literary works, music and photography works etc. published on the network. Compared with paper publishing media, network art can spread more easily. "Under the influence of the western thought trend such as postmodernism etc, and with the impellent of science progress, the unique charm of network art becomes more and more obvious. New aesthetic idea is formed step by step, and the brand new age of network artistic creation and aesthetic appreciation has come."(Jiang, 2007). The network art becomes more and more prosperous in recent years. Take the network literature for example, in 1998, The First Touch was a network literary work appearing early. Later, fantasy novels, supernatural thrillers, metropolis emotional novels, grassroots novels and other types of literary works appear in quantity in the network. These network novels are not mature artistically, but have diversified 
styles, original techniques and novel contents in terms of artistic means. The readers are dominated by the youths. "The development of network in China is still in the starting phase, but a powerful strength behind it makes it develop more rapidly than the previous art, and the strength comes from the commercial capital. The commercial operation of network art is formed by the infusion of capital with the result of industrialization of network art dissemination." (Jiang, 2007)

Due to low judgment and bandwagon effect of Chinese netizen subjects, with the impellent of industrialization, these youth network sub-cultural phenomena contrary to mainstream cultural value spread very fast.

\section{The Commerical Characteristics of the Youth Network Subculture in China}

Youth network subculture and commercial interests are not entirely different. They are each other's objects mutually. Since the subjects of Chinese netizens are the youths and the consumption subjects of network culture industry are also the youths, youth network subculture can be easily combined with commercial interests.

The injection of commercial capital and marketing idea makes network subculture become the profitable field domain soon. Drive by commercialization, large quantities of writers appear in network literary creation. They cater to readers' taste and carry out mass production in the way of production line. In China, some network celebrities such as "sister Furong" and "Luo Yufeng" have appeared. They together with commercial companies to make sensational effect so as to shoot commercial advertisements, films and photo albums for gaining high appearance fees and profits. Network literature, network idol and network youth cartoon are common commercial operation modes in China's network culture industry.

Take network literature for example. China has such famous Chinese reading websites as qidian.come, ronghusxia.com, honhxiutianxiang.com, XXSY.net. In some main web portals in China such as Netease, Sohu and Sina also have their own literary reading bases. In China, some famous forums such as tianya, xicihutong and shuimuqinghua have literary bases with original creation. "The various novels such as fantasy novels, gods novels, sentimental novels and honor novels occupies the bookstall on street and book fair in campus almost without the awareness of the public, and such novels are print publication.... The readers around the books almost all are adolescent students, standing or squatting." (Ai, 2008) Lots of merchants focus on the huge market of network literature and make abundant print, because they believe the future increase of readership of youth.

Network literature covers a wide range. Take qidian.com with high click rate for example. Its works involve multiple types such as imaginary, martial arts, urban, historical, military, game, competition and science fictions. The most popular novels among the youths include: literature, martial arts/magical/light novel, psychology/ encouragement, history/ geography, natural science and csrtton. (Wen, 2013)

Most originators of network literature are the common people. Take Netease originality for example. Common people can gain an account number for free on Netease originality and start literary creation, as long as they register an account number with the ID card. In order to attract readers' attention and gain profits through their creation, some network creators will try their best to pursue readers' interests so as to attract theme continuously.

Therefore, the literatures created in the network seem very popular. On the other hand, such works which can cater to readers' interests will not have high literary style so that meteor network literature which the youths like to read is full of black violence literature represented by online game and fantasy, gray literature represented by grave robbery and evil spirits, pink literature represented by love and youth and yellow literature represented by eroticism rather than traditional literature and beneficial literature......" (Li \& Liu, 2013)

The unique psychological feature of the youth makes they tend to be addicted to the network subculture. "On a certain viewpoint, the subject is constantly growing, but the growing in the phase of child and youth are most obvious. Perhaps that is because the subject grows in the sense of not only physiology but also psychology. After the phase, the physical growing would stop and only the psychological growing continue. For the youth, the physical growing and psychological are both necessary, but the two kinds of growing can not synchronize. In such condition, it is really possible that the physical growing is previous to the psychological growing. That makes the phenomenon that the youth's body has lots of changes, but their mentality still stays in the state of the past. So their activities till seem very naive." (Cai, 1979). The psychological characteristic makes the youth can hardly resist the negative effects of network. The results are the misconduct, lack of morality and even criminal act. In order to make more profit, the merchants seldom care about the negative effects. They even product more factors of moral degeneration to attract the youth readers. The market mechanism is harmful to the youth obviously.

Except network literature, network cartoon and network autodyne have similar features. It can be found from network literature phenomena that under the function of commercialization, the effects of youth network 
subculture are deepened. Since most network subjects have weak judgment and tend to let off angers, network subculture is not positive social impetus rich in positive significance and even has many negative factors.

\section{Discussion}

Some consider youth network subculture is not a dreadful monster: "youth subculture which was not comprehended by mainstream society has existed for many years and became an important type early in network - time-travel novel. The mainstream society does not pay attention to these cultures and criticize them with simple words such as 'superficiality' and 'mischievousness'. In fact, the literatures such as 'time-travel', 'fantasy' and 'science fiction' to a large extent dominate youths' reading life. Objectively speaking, a large part of these cultures has positive significance for improving youths' self-identity, social identify and sense of happiness. But the positive significance is ignored by the society due to the strangeness of the form or expression mode." (Zhe, 2011) But we should see the manifestations of Chinese youth subculture in the network in essence resist mainstream culture rich in release and bandwagon effect. The reading value gained by the youths in the network does not come from the contents, but from the form of narration.

In current stage, Chinese youth subculture has the following features: firstly, resist parent culture; secondly, highlight game and release characteristics; youths' interest in using emergent media. Under the function of commercialization and netizens' bandwagon effect, these features will be continuously deepened.

In network world, network communication and influences of grassroots and common people are enhancing increasingly, while the influence of authoritative information senders is weakening. Take microblog for example. Microblog users can be classified into microblog masters, popular grassroots, common grassroots and media users. The fact has proven that in the real society, the microblog communication effect of the dominating groups in power discourse space is much lower than that of common grassroots users, while "the grassroots in the weak position in power discourse space in the real society may become the dominant force of re-construction of microblog interaction." (Xia, 2010)

Network youth subculture is characterized by marginality, opposability and subversiveness. These characteristics exactly comply with " $180^{\circ}$ effect" of network culture individualization. In other words, the non-dominant contents in real power discourse space show great influence in network, just like $180^{\circ}$ over turn. "The network is a virtual world featured by anti-centralization and non-concentration of power.It contempts the authority, eliminates the differences of grades, and likes to sneering the godlike and subvert the classics. The solemn images and discourses of mainstream ideology become the object of netizens' ridicule....The heaviness and suppression of the youth caused by existing order are removed. The vigorous individuality is brightened. The condition of independence and indulgence is realized." (Ai, 2008). Drived by commercialization, the negative effects of network youth subculture will be continuously amplified.

\section{Conclusion}

In the youth stage, human mentality becomes nature from immaturity and become adults from children. The main feature in this age grade is full of beans, but meanwhile their self-control ability is poor and they have strong curiosity, ready try new things. In this period, the youths create large quantities of new cultural phenomena, especially in new media field. Different from previous paper media, mew media not just has infinite network contents, but also can provide interactive platform for the youths. Here, the youths are not just the users and consumers of cultures, but also the creators and producers.

However, since Chinese traditional educational mode is autocratic, the depression the youths suffer in their growth stage is heavy. Their physiological changes make them in mental weaning period. In this stage, they urgently need to get rid of their dependence on their parents and teachers. They can easily find another identity in network and can gain mental satisfaction more easily. So, the youths can easily form a unique cultural phenomenon resisting traditional culture in the adult world.

Compared with youth subculture appearing in 1950s-1960s, youth network sub-cultural phenomenon in China's current stage is actively constructed by commercialization and continuously deepened in commercial activities. This is not a political campaign, but the grand banquet of network couture industry. Although some economic profits are brought, it contains many adverse factors for social development.

\section{References}

Ai, H. (2008). Research of the Influence of Network Literature on the Youth growing and the Countermeasure. Journal of Shandong Youth Administrative Cadres College, (3), 26-29.

Cai, D. (1979). Criminal Psychology. Liming Cultural Undertaking Publishing House. 
Cai, F., \& Liu, T. (2008). Kuso on Internet: New Front of Postmodernism Mass Culture. Shi Ji Qiao, (6), 88-90

Chen, H., \& Zhang, Y. (2013). On the Non-mainstream Culture of Internet. Journal of Changchun Industry University, (4), 143-146.

CNNIC. (2013). CNNIC 32nd Internet Report. Retrieved July 17, 2013, from http://tech.163.com/special/cnnic32

Hu, T. (2008). Kuso and Youth Subculture. Chinese Youth Study, (6), 5-12.

Jiang, B. (2007). The network art Brought up by the Network Communication. Academic Research, (11), 143-146.

Li, W., \& Lv, F. (2013), Analysis of Internet Cultural Consumption Based on the Idea of LOHAS. Journal of Fujian Normal University, (2), 151-161.

Li, X. (2008). Non-mainstream on Internet and Ideological and Political Education of the Youth. Legal System and Society, (10), 314-315.

Li, Y., \& Liu, Z. (2013). On the Characteristic of Youth Network Literature Reading. Research on Library Science, (10), 31-38.

Qiao, L. (2010). On the Juvenile Subculture under the Environment of New Media and Its Value Significance. Master's Thesis.

Wang, C. (2013). Psychological Research on Self-timer on Internet. Assistant of Editor, (8), 77-84.

Wen, H. (2013). Shanghai Teenagers Like Reading the Printed Works; The Literature Workshop and Fantasy Novels Are Welcome. Retrieved November 9, 2013, from http://www.news365.com.cn/xwzx/sh/201311/t20131109_1699322.html

Xia, Y. (2010). The Structure and Mechanism of Interactivity of Micro Blog: The Empirical Study on Sina Micro Blog. Study on News and communication, (4), 60-69.

Zhe, J. (2011, March 11). Criticizing Time-travel TV Series While Enjoying it. Zhejiang Daily.

Zheng, P., Pu, Y., \& Sun, Y. (2013). The Research Report of Youth Subculture's propagation path: The Survey Based on the 21 Universities in Jiangsu. Chinese Youth Study, (9), 18-24.

\section{Copyrights}

Copyright for this article is retained by the author(s), with first publication rights granted to the journal.

This is an open-access article distributed under the terms and conditions of the Creative Commons Attribution license (http://creativecommons.org/licenses/by/3.0/). 